\title{
Does smartphone overuse affect functional gastrointestinal disorders?
}

Jee Hyun Lee, MD, PhD

Department of Pediatrics, Korea University Ansan Hospital, Korea University College of Medicine, Ansan, Korea

\section{Key message}

Functional gastrointestinal disorders are common disorders characterized by persistent and recurrent gastrointestinal symptoms. Pathophysiological mechanisms have been suggested, including intestinal microbiota, altered intestinal permeability and motility, dietary effects, sensory abnormalities, and brain-gut dysregulation. Lifestyle factors such as diet, sleep, affect, and physical activity might function as moderators.

I read recent letter of Cinquetti et al. ${ }^{1)}$ about smartphone use in functional gastrointestinal disorders (FGIDs) in adolescents with great interest. They reported that the prevalence of FGIDs was $30.9 \%$ in Italian adolescents (11-14 years of age) and that FGIDs are correlated with excessive smartphone use.

The prevalence of FGIDs differed among studies, and interstudy comparisons are limited. ${ }^{2-4)}$ There are several potential explanations for this variability, including cultural differences, social reporting sensitivities, ethnic diversity, and differences in genetics and dietary habits. There are also differences in research methods among studies, especially in participant age, questionnaire sensitivity, and diagnostic criteria. It is difficult to compare studies due to the heterogeneity of diseases that are diagnosed through clusters of symptoms without the need for confirmation. The study of Saps et al. ${ }^{5)}$ included children 8-18 years of age and used a self-reported questionnaire. Robin et al. ${ }^{6}$ enrolled mothers of children aged $0-18$ years and used an online survey about their children's gastrointestinal symptoms (Table 1).

The pathophysiological mechanisms that play a role in FGIDs include gut-brain dysfunction, chronic infection, intestinal microbiota, low-grade mucosal inflammation, altered intestinal permeability and bile salt metabolism, abnormal serotonin metabolism, and genetic factors. These factors are modulated by environmental factors such as diet. ${ }^{7)}$ Comorbid mood and sleep disorders with FGIDs have been suggested with respect to the brain-gut interaction. ${ }^{8)}$ Adolescents with FGIDs suffer negative effects and have shorter sleep durations than their normal controls. ${ }^{9)}$ Smartphone dependence in adolescents was proposed to be linked to aberrations in the brain network through amygdala hypercentrality. ${ }^{10)}$ Amygdala-mediated mechanisms for stress-induced visceral hypersensitivity were demonstrated, and this common pathway might be a clue to the brain-gut axis pathogenesis of smartphone addiction-affected adolescents with FGIDs. ${ }^{11)}$

Smartphone use habits are thought to influence lifestyle and behavior. Excessive smartphone use interferes with adequate sleep and negatively affects regular eating and proper physical activity. ${ }^{12)}$ Analyzing known causal factors such as diet, sleep, affect, and physical activity according to smartphone usage habits

Table 1. Prevalence of pediatric functional gastrointestinal disorders

\begin{tabular}{|c|c|c|c|c|c|c|}
\hline Study & Country & Study design & $\begin{array}{l}\text { Sample } \\
\text { size (n) }\end{array}$ & $\begin{array}{l}\text { Diagnostic } \\
\text { criteria }\end{array}$ & $\begin{array}{c}\text { Age (yr), } \\
\text { mean (range) }\end{array}$ & Prevalence \\
\hline $\begin{array}{l}\text { Cinquetti et al.., } \\
2020\end{array}$ & Italy & $\begin{array}{l}\text { Cross-sectional, school based, self- } \\
\text { reported QPGS-IV }\end{array}$ & 1,594 & Rome IV & $12.8(11-14)$ & $30.9 \%$ \\
\hline $\begin{array}{l}\text { Saps et al.., } \\
2018\end{array}$ & Colombia & $\begin{array}{l}\text { Cross-sectional, school based, self- } \\
\text { reported QPGS-IV }\end{array}$ & 3,567 & Rome IV & 13.7 (8-18) & $21.1 \%$ \\
\hline $\begin{array}{l}\text { Robin et al., }{ }^{6)} \\
2018\end{array}$ & USA & $\begin{array}{l}\text { Cross-sectional, online survey, parental } \\
\text { reported RIV-PDQ }\end{array}$ & 1,255 & Rome IV & $8.3(0-18)$ & $\begin{array}{l}24.7 \% \text { (infants and toddler) } \\
25.0 \% \text { (children and adolescents) }\end{array}$ \\
\hline $\begin{array}{l}\text { Lewis et al., }{ }^{2)} \\
2016\end{array}$ & USA & $\begin{array}{l}\text { Cross-sectional, online panel community, } \\
\text { parental reported QPGS-RIII }\end{array}$ & 949 & Rome III & $10.6(4-18)$ & $23.1 \%$ \\
\hline $\begin{array}{l}\text { Scarpato et al., } \\
2016\end{array}$ & $\begin{array}{l}\text { Mediterranean } \\
\text { region of Europe }\end{array}$ & $\begin{array}{l}\text { Cross-sectional, school based, self- } \\
\text { reported QPGS-RIII (4-10 yr), parenteral } \\
\text { reported QPGS-RIII (11-18 yr) }\end{array}$ & 13,750 & Rome III & $\begin{array}{c}7.7(4-10) \\
13.8(11-18)\end{array}$ & $\begin{array}{l}20.7 \%(4-10 y r) \\
26.6 \%(11-18 y r)\end{array}$ \\
\hline
\end{tabular}

QPGS-IV, Questionnaire on Pediatric Gastrointestinal Symptoms Rome IV; RIV-PDQ, Rome IV Pediatric Diagnostic Questionnaire; QPGS-RIII: Questionnaire on Pediatric Gastrointestinal Symptoms Rome III.

Corresponding author: Jee Hyun Lee, MD, PhD, Department of Pediatrics, Korea University Ansan Hospital, 123, Jeokgeum-ro, Danwon-gu, Ansan 15355, Korea 凶Email: izzihn@gmail.com, https://orcid.org/0000-0002-4318-2487

Received: 27 November, 2020, Revised: 18 December, 2020, Accepted: 18 December, 2020

This is an open-access article distributed under the terms of the Creative Commons Attribution Non-Commercial License (http://creativecommons.org/licenses/by$\mathrm{nc} / 4.0 /$ ) which permits unrestricted non-commercial use, distribution, and reproduction in any medium, provided the original work is properly cited.

Copyright (c) 2021 by The Korean Pediatric Society 
will help more clearly explain the effect of smartphone use on FGID. From the multiple regression model presented by the authors, smartphone addiction showed a higher odds ratio than specific diet factors in the presence of FGIDs. This result might suggest as mentioned above that smartphone overuse is linked to a very wide range of lifestyle risk factors of FGIDs such as sleep, physical activity, and affect.

These days, especially during the coronavirus outbreak, nonface-to-face relationships are socially encouraged, and the use of digital media by children and adolescents is increasing for various purposes, including education. On the other hand, there are concerns about the possible adverse effect on the formation of beneficial social relationships, adequate and quality sleep habits, adequate physical activity, and regular and healthy eating habits. Digital media, including smartphones, are already a necessity in our daily lives, and their proper use is a difficult task for everyone. Accordingly, I fully agree with the aim of this study of identifying the relationship between smartphone overuse and FGIDs in children and adolescents.

The habit of using digital media will affect the development and growth of children and adolescents in many aspects and is expected to affect the prevalence of various diseases. However, for this habit to be sufficiently identified as a causative or influential factor, evidence and explanations based on a pathophysiologic mechanism should also be made through future studies.

\section{Footnotes}

Conflicts of interest: No potential conflicts of interest relevant to this article are reported.

See the article "Functional gastrointestinal disorders and smartphone use in adolescent" via https://doi.org/10.3345/cep.2020. 01326.

\section{References}

1. Cinquetti M, Biasin M, Venitimiglia M, Balanzoni L, Signorelli D, Pietrobelli A. Functional gastrointestinal disorders and smartphone use in adolescents. Clin Exp Pediatr 2020 [Epub]. https://doi.org/10.3345/cep. 2020.01326.

2. Lewis ML, Palsson OS, Whitehead WE, van Tilburg MAL. Prevalence of functional gastrointestinal disorders in children and adolescents. J Pediatr 2016;177:39-43.

3. Scarpato E, Kolacek S, Jojkic-Pavkov D, Konjik V, Živković N, Roman E, et al. Prevalence of functional gastrointestinal disorders in children and adolescents in the mediterranean region of europe. Clin Gastroenterol Hepatol 2018;16:870-6.

4. Peralta-Palmezano JJ, Guerrero-Lozano R. Prevalence of functional gastrointestinal disorders in school children and adolescents. Korean J Gastroenterol 2019;73:207-12.

5. Saps M, Velasco-Benitez CA, Langshaw AH, Ramírez-Hernández CR. Prevalence of functional gastrointestinal disorders in children and adolescents: comparison between Rome III and Rome IV criteria. J Pediatr 2018;199:212-6.

6. Robin SG, Keller C, Zwiener R, Hyman PE, Nurko S, Saps M, et al. Prevalence of pediatric functional gastrointestinal disorders utilizing the Rome IV criteria. J Pediatr 2018;195:134-9.

7. Holtmann G, Shah A, Morrison M. Pathophysiology of functional gastrointestinal disorders: a holistic overview. Dig Dis 2017;35 Suppl 1:5-13.

8. Bouchoucha M, Mary F, Bon C, Bejou B, Airinei G, Benamouzig R. Sleep quality and functional gastrointestinal disorders. A psychological issue. J Dig Dis 2018;19:84-92.

9. Monzon AD, Cushing CC, Friesen CA, Schurman JV. The association between affect and sleep in adolescents with and without FGIDs. J Pediatr Psychol 2020;45:110-9.

10. Tymoflyeva O, Yuan JP, Kidambi R, Huang CY, Henje E, Rubinstein ML, et al. Neural correlates of smartphone dependence in adolescents. Front Hum Nerosci 2020;14:564629.

11. Meerveld BG. Johnson AC. Mechanisms of stress-induced visceral pain. J Neurogastroenterol Motil 2018;24:7-18.

12. Demirci K, Akgönül M, Akpinar A. Relationship of smartphone use severity with sleep quality, depression, and anxiety in university students. J Behav Addict 2015;4:85-92.

How to cite this article: Lee JH. Does smartphone overuse affect functional gastrointestinal disorders? Clin Exp Pediatr 2021;64:471-7. https://doi.org/10.3345/cep.2020.01935 